Enferm Bras 2020;19(1):58-66

https://doi.org/10.33233/eb.v19i1.1651

\title{
REVISÃO \\ Uso da hipotermia induzida após parada cardiorrespiratória
}

Ionara Silva*, Joyce Carolynne Silva*, Karen Rayara Bezerra Lima*, Daniele Vieira Dantas, D.Sc. ${ }^{* \star}$, Rodrigo Assis Neves Dantas, D.Sc. ${ }^{* \star}$, Maria do Carmo de Oliveira Ribeiro, D.Sc. ${ }^{* \star \star}$

${ }^{*}$ Enfermeira pela Universidade Federal do Rio Grande do Norte/UFRN, Centro de Ciências da Saúde, Departamento de Enfermagem, Natal/RN, ${ }^{* *}$ Enfermeira, Pós-Doutora em Enfermagem pela Universidade Federal de Sergipe, Professora Adjunta do Departamento de Enfermagem da Universidade Federal do Rio Grande do Norte/UFRN, Natal/RN, ${ }^{* \star \star E n f e r m e i r o, ~ P o ́ s-D o u t o r ~ e m ~}$ Enfermagem pela Universidade Federal de Sergipe, Professor Adjunto do Departamento de Enfermagem da Universidade Federal do Rio Grande do Norte/UFRN, Natal/RN, ${ }^{\star \star * \star}$ Enfermeira, Professora Adjunta do Departamento de Enfermagem da Universidade Federal de Sergipe/UFS, Aracajú/SE

Recebido em 14 de dezembro de 2018; aceito em 15 de janeiro de 2020.

Correspondência: Rodrigo Assis Neves Dantas, Rua Petra Kelly, 61, Geraldo Galvão Residencial, casa 48 Nova Parnamirim 59152-330 Parnamirim RN

Rodrigo Assis Neves Dantas: rodrigoenf@yahoo.com.br

Ionara Silva: ionarasilva13@gmail.com

Joyce Carolynne Silva: joyceecarol@gmail.com

Karen Rayara Bezerra Lima: karen_rayara@hotmail.com

Daniele Vieira Dantas: daniele00@hotmail.com

Maria do Carmo de Oliveira Ribeiro: enffer2@gmail.com

\section{Resumo}

Introdução: A parada cardiorrespiratória é definida como a cessação abrupta da atividade mecânica do coração. Os indivíduos que conseguem sobreviver podem adquirir danos neurológicos irreversíveis. A indução da hipotermia visa a diminuição do metabolismo cerebral, limitação da lesão miocárdica e sistêmica. Objetivo: Identificar as informações recentes e as principais medidas a serem tomadas durante o uso de hipotermia induzida em ambiente hospitalar após ocorrência de parada cardiorrespiratória. Métodos: Revisão da literatura científica do tipo integrativa empírica. A busca foi realizada em outubro de 2017, na Biblioteca Virtual em Saúde, bases de dados da Literatura Latino-Americana e do Caribe de Informação em Ciências da Saúde; na Medical Literature Analysis and Retrieval System Online, Scientific Electronic Library Online, além de buscas realizadas no Pubmed. Resultados: Os estudos selecionados trazem diversas contribuições sobre o uso da hipotermia induzida em ambiente hospitalar. Estes foram divididos nas seguintes categorias de análise: Desfecho neurológico e fatores predisponentes de resultados após a HT, Medidas eficazes de cuidado durante a HT e, por fim, os Efeitos da hipertermia de rebote após a HT. Conclusão: Os resultados demonstraram a necessidade da atualização frequente dos profissionais sobre o tema, com o intuito de qualificar a assistência, baseando-se em evidências.

Palavras-chave: parada cardíaca, reanimação cardiopulmonar, hipotermia induzida, emergências, cuidados críticos.

\footnotetext{
Abstract

Use of induced hypothermia after cardiac arrest

Introduction: Cardiorespiratory arrest is defined as the abrupt cessation of mechanical activity of the heart. Individuals who can survive can have irreversible neurological damage. The induction of hypothermia is aimed at reducing cerebral metabolism, limiting myocardial and systemic injury. Objective: To identify the recent information and the main measures to be taken during the use of induced hypothermia in a hospital environment after the occurrence of cardiorespiratory arrest. Methods: Review of the literature of empirical integrative type. The search was conducted in October 2017, in the Virtual Health Library, databases of Latin American and Caribbean Literature on Health Sciences Information; in the Medical Literature Analysis and Retrieval System Online,
} 
Scientific Electronic Library Online, in addition to searches made in Pubmed. Results: The selected studies bring several contributions about the use of hypothermia induced in a hospital environment. These were divided into the following categories of analysis: Neurological outcome and predisposing factors of outcomes after HT, Effective care measures during HT, and, finally, Effects of rebound hyperthermia after HT. Conclusion: The results demonstrated the need for frequent updating of professionals on the subject, in order to qualify care, based on evidence.

Keywords: heart arrest, cardiopulmonary resuscitation, hypothermia, induced, emergencies, critical care.

\section{Resumen \\ Uso de hipotermia inducida después de paro cardiorrespiratorio}

Introducción: El paro cardiorrespiratorio se define como el cese abrupto de la actividad mecánica del corazón. Las personas que logran sobrevivir pueden adquirir daños neurológicos irreversibles. La inducción de hipotermia tiene como objetivo disminuir el metabolismo cerebral, limitando las lesiones miocárdicas y sistémicas. Objetivo: Identificar la información reciente y las principales medidas a tomar durante el uso de la hipotermia inducida en un entorno hospitalario después de la aparición de un paro cardiorrespiratorio. Métodos: Revisión de la literatura científica del tipo empírico integrador. La búsqueda se realizó en octubre de 2017, en la Biblioteca Virtual en Salud, bases de datos de Literatura Latinoamericana y del Caribe sobre Información en Ciencias de la Salud; en Medical Literature Analysis and Retrieval System Online, Scientific Electronic Library Online, así como en las búsquedas realizadas en Pubmed. Resultados: Los estudios seleccionados aportan varias contribuciones sobre el uso de la hipotermia inducida en un entorno hospitalario. Estos se dividieron en las siguientes categorías de análisis: resultado neurológico y factores predisponentes para los resultados después de la TH, medidas efectivas de atención durante la TH y, finalmente, los efectos de la hipertermia de rebote después de la TH. Conclusión: Los resultados demostraron la necesidad de una actualización frecuente de los profesionales sobre el tema, a fin de calificar la asistencia, con base en la evidencia.

Palabras-clave: paro cardíaco, reanimación cardiopulmonar, hipotermia inducida, emergencias, cuidados críticos.

Introdução

A Parada Cardiorrespiratória (PCR) é definida como a cessação abrupta da atividade mecânica do coração e é diagnosticada através da avaliação de três parâmetros: responsividade, respiração e pulso. Em um indivíduo com PCR esses três parâmetros encontram-se ausentes [1].

A etiologia da PCR é classificada em $5 \mathrm{H}$ s e 5Ts, sendo: hipotermia, hipovolemia, hipóxia, $\mathrm{H}_{+}$(acidose), hipercalemia/hipocalemia, tensão no tórax (pneumotórax), tamponamento cardíaco, tromboembolismo pulmonar, trombose coronariana e toxicidade [2].

Frente a uma situação de parada cardiorrespiratória, alguns passos são estabelecidos para que haja sucesso na prática de reanimação. O Suporte Básico de Vida (SBV) define a sequência primária das ações através do CABD. O C (Circulation) consiste na ênfase em compressões torácicas de boa qualidade; enquanto o A (Airway) trata-se da abertura das vias aéreas, deixando-as pérvias. O B (Breathing), por sua vez, refere-se à boa ventilação e o $\mathrm{D}$ (Defibrillation) à desfibrilação em casos de ritmos chocáveis (Fibrilação Ventricular - FV e Taquicardia Ventricular sem Pulso - TVSP). Por sua vez, no Suporte Avançado de Vida em Cardiologia (SAVC), além de um SBV bem executado, faz-se necessária a utilização de procedimentos invasivos e administração de drogas [3].

Embora inúmeros avanços tenham sido alcançados nos últimos anos referentes à prevenção e tratamento da PCR, a mortalidade no Brasil ainda continua elevada [4]. Estudos revelam que a maioria das mortes acontecem durante as primeiras $24 \mathrm{hs}$ após o episódio de parada cardíaca e a taxa de sobrevivência após a alta hospitalar varia de 9,5\% (PCR hospitalar) para $24,2 \%$ em casos de PCR extra-hospitalar. Os indivíduos que conseguem sobreviver podem adquirir danos neurológicos irreversíveis, com perdas de habilidades funcionais, cognitivas, emocionais e diminuição da qualidade de vida [5].

$A$ incidência de mortes e o prognóstico pós-PCR estão diretamente relacionados às condições e causa da PCR, e ao emprego correto das manobras de reanimação cardiopulmonar. Portanto, torna-se necessário que haja um atendimento rápido, seguro e eficaz [6-7].

Os cuidados pós-PCR devem ser implementados tão logo haja retorno circulatório espontâneo (RCE). Estes são complexos e tem o objetivo reduzir, inicialmente, a mortalidade 
associada à instabilidade hemodinâmica, bem como diminuir os riscos de lesão neurológica e disfunção nos demais órgãos e sistemas [4]. Para tanto, é essencial que seja determinada a causa da parada e seu tratamento adequado [8].

Dentre os cuidados pós-PCR podem ser citadas as medidas de suporte gerais, utilizando a monitorização hemodinâmica e cerebral, em ambiente de terapia intensiva (oximetria de pulso, eletrocardiograma contínuo, débito urinário, pressão arterial invasiva, exames laboratoriais, ecocardiograma, eletroencefalograma contínuo, tomografia do crânio, dentre outros). Além da monitorização, a oferta de oxigênio, através de via aérea avançada se faz necessário. Uma vez que o paciente esteja estabilizado, um acesso venoso central deve ser garantido para que haja a administração de drogas vasoativas em eventuais necessidades. Caso o paciente prossiga com pressão arterial sistólica inferior a $90 \mathrm{mmHg}$, a administração de solução salina deve ser iniciada. Sendo a causa da parada fibrilação ventricular ou taquicardia ventricular sem pulso, drogas antiarrítmicas devem ser administradas. Além destes, a Hipotermia Terapêutica (HT) também é um método a ser empregado em casos de pacientes comatosos [4].

A indução da hipotermia visa a diminuição do metabolismo cerebral, limitação da lesão miocárdica e sistêmica [9]. A temperatura alvo limita-se entre $32^{\circ} \mathrm{C}$ e $36^{\circ} \mathrm{C}$, mantida constantemente em um período de $24 \mathrm{~h}$ [3]. Algumas técnicas podem ser adotadas para 0 estabelecimento do resfriamento corpóreo. $O$ uso de colchões com cobertura que transmite ar frio pelo corpo inteiro é uma das técnicas empregadas. Caso este método não seja suficiente, o uso de fluidos intravenosos resfriados a $4^{\circ} \mathrm{C}$ também pode ser implementado. Além destas, outras técnicas podem ser utilizadas, no entanto envolvem diversas dificuldades e não são tão utilizados, como o resfriamento por lavagem peritoneal e pleural e o resfriamento extracorpóreo do sangue [10].

Tendo em vista as constantes atualizações sobre o uso da hipotermia induzida e a necessidade de oferecer um tratamento pós-PCR adequado ao paciente, sem a ocorrência de iatrogenias, faz-se necessário o desenvolvimento de estudos como este para que as últimas informações sobre o tema estejam ao alcance dos profissionais da saúde e, assim, estes possam dispor da utilização das novas técnicas, bem como obter conhecimento dos benefícios e malefícios decorrentes da utilização da hipotermia induzida.

Desse modo, o objetivo deste artigo consiste em identificar as informações recentes e as principais medidas a serem tomadas durante o uso de hipotermia induzida em ambiente hospitalar após ocorrência de parada cardiorrespiratória.

\section{Material e métodos}

O presente trabalho consiste em uma revisão da literatura científica do tipo integrativa empírica, a qual permite a identificação de resultados primários, sejam estes qualitativos ou quantitativos, com consequente desenvolvimento de novas teorias através da análise e relação entre os resultados. Durante o seu desenvolvimento, foram seguidos os seguintes passos: 1) Identificação conceitual do problema; 2) Formulação da questão norteadora e do objetivo da revisão; 3) Descrição da metodologia da revisão; 4) Análise e interpretação dos dados primários; 5) Apresentação dos resultados; 6) Interpretação e discussão dos resultados; 7) Divulgação dos resultados [11].

Com base na questão de pesquisa: "Quais as contribuições das pesquisas recentes sobre o uso da hipotermia terapêutica após uma parada cardiopulmonar?", a busca foi realizada no mês de outubro de 2017, na Biblioteca Virtual em Saúde (BVS), nas bases de dados da Literatura Latino-Americana e do Caribe de Informação em Ciências da Saúde (Lilacs); na Medical Literature Analysis and Retrieval System Online (Medline), Scientific Electronic Library Online (Scielo), além de buscas realizadas no Pubmed.

Os artigos foram pesquisados por meio dos descritores "parada cardíaca", "reanimação cardiopulmonar" e "hipotermia induzida", segundo a classificação dos Descritores em Ciências da Saúde (DeCS), combinados pelo conector booleano "AND".

Foi utilizado como critérios de inclusão artigos publicados nos últimos 5 anos (20132017), com disponibilidade integral do texto, no idioma inglês, espanhol ou português. Excluíramse artigos que consistiam em outras revisões, cartas aos editores de periódicos e que apresentavam aspecto clínico de etiologia ou predição, o resultado obtido foi de 29 trabalhos elegíveis nas bases de dados acessadas. (Gráfico 1).

Após leitura do resumo de cada artigo, selecionaram-se apenas os que mais traziam contribuições sobre o uso da hipotermia induzida, sendo escolhidos 16 [13-28] artigos. 
Os dados foram coletados e caracterizados em uma planilha do Microsoft Excel, de acordo com o título, objetivo, amostragem, conclusão e nível de evidência, o qual foi possível identificar a credibilidade científica, fundamentado na categorização dos mesmos, como apresentado no Quadro 1.

Quadro 1 - Classificação dos Níveis de Evidência (NE) [12].

\begin{tabular}{|c|l|}
\hline Nível & \multicolumn{1}{|c|}{ Descrição da evidência } \\
\hline $\mathbf{1}$ & $\begin{array}{l}\text { Evidências provenientes de revisão sistemática ou metanálise baseadas em } \\
\text { ensaios clínicos randomizados controlados. }\end{array}$ \\
\hline $\mathbf{2}$ & $\begin{array}{l}\text { Evidência derivada de pelo menos um ensaio clínico randomizado controlado, bem } \\
\text { delineado. }\end{array}$ \\
\hline $\mathbf{3}$ & Evidência obtida de ensaio clínico bem delineado, sem randomização. \\
\hline $\mathbf{4}$ & Evidência proveniente de estudo de coorte e de caso-controle bem delineado. \\
\hline $\mathbf{5}$ & Evidência originária de revisão sistemática de estudos descritivos e qualitativos. \\
\hline $\mathbf{6}$ & Evidência derivada de um único estudo descritivo ou qualitativo. \\
\hline $\mathbf{7}$ & Evidência oriunda de opiniões de autoridades ou relatório de comitês de especialistas \\
\hline
\end{tabular}

Os autores abordados, no presente estudo, foram devidamente referenciados, respeitando e identificando as fontes de pesquisa, considerando eticamente a propriedade intelectual dos textos analisados.

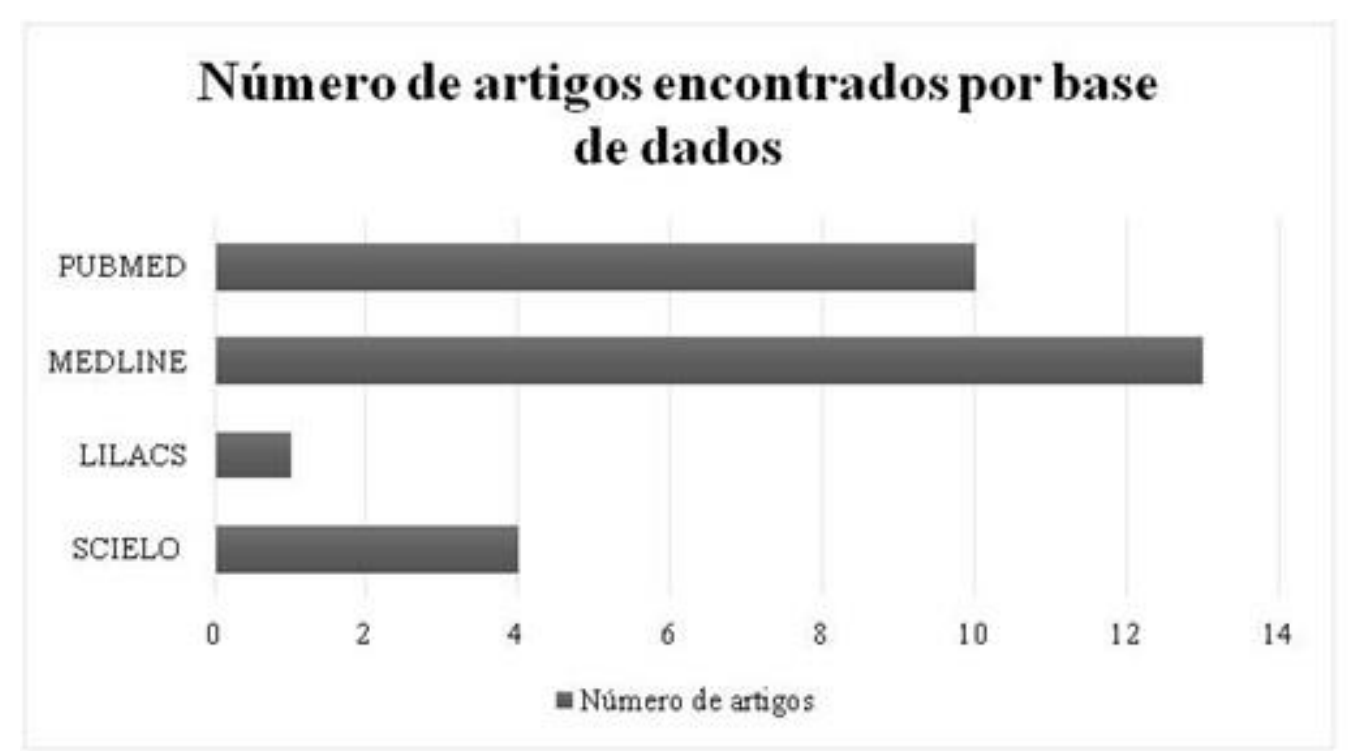

Gráfico 1 - Número de artigos encontrados por base de dados.

\section{Resultados}

A identificação dos 16 artigos resultantes foi feita em forma de quadro para facilitar a avaliação do leitor. 
Quadro 2 - Caracterização das publicações quanto ao autor, ano, periódico, objetivo e nível de evidência.

\begin{tabular}{|c|c|c|c|c|}
\hline Referência/ano & $\begin{array}{l}\text { Base de } \\
\text { dados }\end{array}$ & Periódico & Objetivo & NE \\
\hline $\begin{array}{l}\text { Tetsuhara K et } \\
\text { al., } 2016[13]\end{array}$ & Medline & $\begin{array}{l}\text { American } \\
\text { Journal of } \\
\text { Emergency } \\
\text { Medicine }\end{array}$ & $\begin{array}{l}\text { Determinar se a acidemia severa }(\mathrm{pH}<7,2) \text { ao } \\
\text { chegar no departamento de emergência é um } \\
\text { fator preditivo para os resultados neurológicos } \\
\text { de pacientes submetidos à HT pós PCR. }\end{array}$ & 4 \\
\hline $\begin{array}{l}\text { Eid SM et al., } \\
2016[14]\end{array}$ & Medline & Resuscitation & $\begin{array}{l}\text { Investigar os padrões de "despertar" } \\
\text { neurológico em pacientes com PCR extra- } \\
\text { hospitalar, usando diferentes critérios para } \\
\text { prognóstico após a parada. }\end{array}$ & 4 \\
\hline $\begin{array}{l}\text { Ryoo SM et al., } \\
2015[15]\end{array}$ & Medline & $\begin{array}{l}\text { Critical Care } \\
\text { Medicine }\end{array}$ & $\begin{array}{l}\text { Avaliar a relação entre o número de lesões } \\
\text { cerebrais e o desfecho neurológico em } \\
\text { pacientes submetidos à HT pós PCR extra- } \\
\text { hospitalar. }\end{array}$ & 4 \\
\hline $\begin{array}{l}\text { Holzinger U et } \\
\text { al., } 2015 \text { [16] }\end{array}$ & Medline & Critical Care & $\begin{array}{l}\text { Correlacionar o gasto energético em repouso e } \\
\text { as taxas de oxidação do substrato com a HT e } \\
\text { resultado neurológico pós PCR. }\end{array}$ & 4 \\
\hline $\begin{array}{l}\text { Williams ML, } \\
\text { Nolan JP, } 2014 \\
{[17]}\end{array}$ & Medline & Resuscitation & $\begin{array}{l}\text { Determinar se os pacientes submetidos à HT } \\
\text { após PCR toleram nutrição enteral precoce. }\end{array}$ & 4 \\
\hline $\begin{array}{l}\text { Ørbo M et al., } \\
2014 \text { [18] }\end{array}$ & Medline & Resuscitation & $\begin{array}{l}\text { Avaliar desfecho cognitivo de sobreviventes de } \\
\text { PCR extra hospitalar de causa cardíaca. }\end{array}$ & 6 \\
\hline $\begin{array}{l}\text { Stær-Jensen H } \\
\text { et al., } 2014 \text { [19] }\end{array}$ & Medline & $\begin{array}{l}\text { Critical Care } \\
\text { Medicine }\end{array}$ & $\begin{array}{l}\text { Explorar a associação entre a bradicardia } \\
\text { durante a HT e o desfecho neurológico de } \\
\text { pacientes comatosos pós PCR. }\end{array}$ & 4 \\
\hline $\begin{array}{l}\text { Kamps MJ et } \\
\text { al., } 2013 \text { [20] }\end{array}$ & Medline & $\begin{array}{l}\text { Intensive Care } \\
\text { Medicine }\end{array}$ & $\begin{array}{l}\text { Avaliar a sensibilidade e a taxa de falsos } \\
\text { positivos do exame neurológico para prever } \\
\text { resultados ruins em pacientes adultos tratados } \\
\text { com HT. }\end{array}$ & 1 \\
\hline $\begin{array}{l}\text { Winters SA et } \\
\text { al., } 2013 \text { [21] }\end{array}$ & Medline & Resuscitation & $\begin{array}{l}\text { Descrever a relação entre a incidência de } \\
\text { hipertermia e a sobrevivência a curto prazo ou } \\
\text { dificuldade neurológica }\end{array}$ & 6 \\
\hline $\begin{array}{l}\text { Cho HJ et al., } \\
2013 \text { [22] }\end{array}$ & Medline & $\begin{array}{l}\text { American } \\
\text { Journal of } \\
\text { Emergency } \\
\text { Medicine } \\
\end{array}$ & $\begin{array}{l}\text { Descrever caso clínico de hemorragia fatal, no } \\
\text { tronco encefálico, após a HT. }\end{array}$ & 6 \\
\hline $\begin{array}{l}\text { Gebhardt K et } \\
\text { al., } 2013 \text { [23] }\end{array}$ & Medline & Resuscitation & $\begin{array}{l}\text { Avaliar a prevalência de febre nas primeiras } 48 \\
\text { horas após a parada cardíaca e seu efeito nos } \\
\text { resultados. }\end{array}$ & 5 \\
\hline $\begin{array}{l}\text { Leão RN et al. } \\
2015 \text { [24] }\end{array}$ & Scielo & $\begin{array}{l}\text { Revista } \\
\text { Brasileira de } \\
\text { Terapia } \\
\text { Intensiva } \\
\end{array}$ & $\begin{array}{l}\text { Determinar a validade de diferentes } \\
\text { marcadores que podem ser utilizados na } \\
\text { detecção de pacientes com mau prognóstico } \\
\text { durante um protocolo de HT. }\end{array}$ & 3 \\
\hline $\begin{array}{l}\text { Storm C, } 2014 \\
\text { [25] }\end{array}$ & Lilacs & $\begin{array}{l}\text { Revista } \\
\text { Brasileira de } \\
\text { Terapia } \\
\text { Intensiva } \\
\end{array}$ & $\begin{array}{l}\text { Analisar o uso da hipotermia e seus desfechos } \\
\text { após ressuscitação cardiopulmonar. }\end{array}$ & 7 \\
\hline $\begin{array}{l}\text { Hifumi T et al., } \\
2015[26]\end{array}$ & Pubmed & $\begin{array}{l}\text { Circulation } \\
\text { Journal of the } \\
\text { Japanese } \\
\text { Circulation } \\
\text { Society }\end{array}$ & $\begin{array}{l}\text { Determinar a associação entre a Escala de } \\
\text { Coma de Glasgow na admissão e os } \\
\text { resultados neurológicos em pacientes com } \\
\text { parada cardíaca ambulatorial que recebem } \\
\text { HT. }\end{array}$ & 3 \\
\hline $\begin{array}{l}\text { Pang PYK et } \\
\text { al., } 2016 \text { [27] }\end{array}$ & Pubmed & $\begin{array}{l}\text { Journal of } \\
\text { Cardiothoracic } \\
\text { Surgery }\end{array}$ & $\begin{array}{l}\text { Avaliar a segurança e a eficácia clínica da HT } \\
\text { por terapêutica em pacientes que receberam } \\
\text { suporte de vida extracorpórea após RCP por } \\
\text { parada cardíaca. }\end{array}$ & 2 \\
\hline $\begin{array}{l}\text { Nielsen } \mathrm{N} \text { et al., } \\
2013 \text { [28] }\end{array}$ & Pubmed & $\begin{array}{l}\text { The New } \\
\text { England } \\
\text { Journal of } \\
\text { Medicine }\end{array}$ & $\begin{array}{l}\text { Comparar duas temperaturas alvo, ambas } \\
\text { destinadas a prevenir a febre em pacientes de } \\
\text { parada cardíaca extra hospitalar. }\end{array}$ & 2 \\
\hline
\end{tabular}


Os estudos selecionados trazem diversas contribuições sobre o uso da hipotermia induzida em ambiente hospitalar. De acordo com suas conclusões e recomendações finais, foram divididos nas seguintes categorias de análise: Desfecho neurológico após a HT, Fatores predisponentes de resultados após a HT, Medidas eficazes de cuidado durante a HT e, por fim, os Efeitos da hipertermia de rebote após a HT.

\section{Desfecho neurológico após a hipotermia terapêutica}

Em estudo com 45 pacientes, foi constatado um resultado cognitivo normal em mais da metade dos sobreviventes quando associado a uma duração reduzida do coma e a indução da HT [18]. Pacientes com retorno da circulação espontânea e submetidos à HT alcançam "despertar" neurológico significativo em 72 horas após a PCR. Entretanto, o uso de diferentes critérios para essa avaliação pode produzir diferentes previsões de prognóstico [14].

Apesar dos benefícios demonstrados e da crença de que alcançar a temperatura alvo da hipotermia rapidamente melhora o prognóstico neurológico, um trabalho desenvolvido com 67 pacientes tratados em Unidade de Terapia Intensiva identificou aumento na mortalidade e piora no desfecho neurológico com a conquista precoce da temperatura alvo [24].

Sabe-se que, após a ocorrência da PCR, o paciente é acometido pela síndrome pósparada, sendo esta caracterizada por disfunções nos sistemas cardiovascular, pulmonar renal e metabólico. A hipotermia, a cada $10 \mathrm{C}$ reduzido, acima da temperatura de $240 \mathrm{C}$, é responsável pela diminuição de $6 \%$ do consumo de oxigênio. Com isso, há a redução de radicais livres de oxigênio, da liberação de aminoácidos excitatórios e intercâmbio de cálcio que corroboram para o aumento do dano mitocondrial e, consequentemente, apoptose [10]. Desse modo, o uso da HT a $33 \%$ é capaz de reduzir o gasto energético em repouso em até $20 \%$ quando comparado a uma temperatura de $360 \mathrm{C}$. Além disso, um estudo que incluiu 25 pacientes demonstrou que, em comparação a pacientes com desfecho neurológico desfavorável, houve diminuição das taxas de oxidação de glicose e aumento da oxidação de gorduras [16].

Em um estudo com 939 adultos inconscientes, após PCR extra hospitalar, buscou-se comparar o controle de temperatura direcionado a $33^{\circ} \mathrm{C}$ ou $36^{\circ} \mathrm{C}\left(n=473 \mathrm{com} 33^{\circ} \mathrm{C}\right.$ e $n=466$ com $36{ }^{\circ} \mathrm{C}$ ). No entanto, foi visto que não houve diferenças significativas entre os valores de temperatura em relação a mortalidade no final do ensaio ou em relação a má função neurológica ou morte aos 180 dias. Nesse estudo não foi encontrado nenhum dano com uma temperatura direcionada de $33^{\circ} \mathrm{C}$ em comparação com $36^{\circ} \mathrm{C}$ [28].

A avaliação neurológica pode ser feita de diversas maneiras, por exemplo, através da Escala de Coma de Glasgow (ECG) e Escala FOUR [29], entretanto, estudos realizados, envolvendo ao todo 1153 pacientes, verificaram que a resposta motora aos estímulos dolorosos e os reflexos corneanos não são uma ferramenta confiável para a predição precoce de resultados ruins em pacientes tratados com HT [20]. O exame ocular parece ter um melhor valor preditivo, uma vez que a ausência de reflexos pupilares pós PCR indica um prognóstico ruim [29]. Em contrapartida, para Hifumi et al. [26] a abertura ocular nem sempre representa a consciência intacta do paciente, devido a indução do coma, o uso de sedativos e a intubação, acreditandose que o componente motor da ECG seja mais útil. Ainda, um trabalho com 172 pacientes confirmou a confiabilidade da ressonância magnética ponderada por difusão em relação a predição do desfecho neurológico de pacientes submetidos à HT após PCR extra-hospitalar [17].

Em outro estudo [25], após o uso da HT leve foi possível reduzir a taxa de pacientes em coma persistente após PCR em até $50 \%$, o que duplicou o número de pacientes que recebem alta com desfechos satisfatórios. No entanto, embora o desfecho tenha se sido satisfatório, o estudo revela que estes resultados não são conquistados apenas com o uso isolado da hipotermia, mas devido a um conjunto terapêutico completo, entre eles: a realização precoce de angiografia invasiva, ventilação otimizada, pressão arterial média, controle glicêmico, monitoramento da diurese e a prevenção de acidose grave.

\section{Fatores predisponentes de resultados neurológicos após hipotermia terapêutica}

A acidose é uma das complicações clássicas da hipotermia e ocorre frequentemente durante ou após a PCR, sendo definida pelo pH arterial inferior a 7,2 [13,30]. Em estudo com 32 pacientes, não foi considerada como um fator preditivo significativo para resultados neurológicos 
após à HT, particularmente com causas cardiogênicas. Desse modo, foi recomendado que o tratamento não fosse retido em pacientes pós-cardíacos com acidose severa [13].

Durante pesquisa com 111 pacientes de um Hospital Universitário, a bradicardia durante a $\mathrm{HT}$ foi associada a um bom resultado neurológico na alta hospitalar. Ela ocorre frequentemente durante a indução da HT. Recomendou-se, portanto, que a bradicardia não fosse tratada agressivamente nesse período, desde que a pressão arterial média, a depuração do lactato e a diurese fossem mantidas em níveis aceitáveis [19].

Os valores esperados para a frequência cardíaca mudam com a temperatura e dispensam a administração de medicamentos ou interrupção da HT. Por outro lado, sabe-se que a bradicardia excessiva faz parte das principais complicações durante a indução de HT, levando, por vezes, a ocorrência de bloqueios atrioventriculares e a interrupção do procedimento [31].

Estudo controlado randomizado evidenciou que a realização da RCP assistida pelo Suporte de Vida Extracorpóreo (SVEc) trouxe melhoras à sobrevivência e aos desfechos neurológicos em comparação com o RCP convencional. A hipotermia terapêutica a $33^{\circ} \mathrm{C}$ mantida durante 24 horas em conjunto com o SVEc foi utilizada para 24 pacientes, dos quais $13(54 \%)$ foram desmamados com sucesso e $12(50 \%)$ receberam alta hospitalar com recuperação neurológica total [27].

\section{Medidas eficazes de cuidado durante a hipotermia terapêutica}

Segundo o protocolo de hipotermia, a administração de nutrição enteral deve ser contínua, desde que tolerada, com uma dose inicial de $20 \mathrm{~mL} / \mathrm{h}$ [24]. A maior parte dos pacientes tratados com HT pós PCR, em uma amostra de 55 pacientes, tolerou uma porção reduzida de nutrição enteral administrada, correspondendo às necessidades nutricionais diárias. O estudo mostrou que a taxa pode ser aumentada à medida que o paciente retorna para a normotermia $\mathrm{e}$ que a maior incidência de vômitos ou regurgitamento ocorreu entre 24 e $48 \mathrm{~h}$ de terapia [17].

A hipotermia aumenta o tempo de coagulação gerando um evento chamado de coagulopatia hipotérmica, o qual não é considerado como causa significativa de hemorragia $[22,32]$. O benefício da HT supera o risco de sangramento, mas o monitoramento da temperatura entre 33 e $35^{\circ} \mathrm{C}$ deve ser contínuo para evitar hipotermia e consequentes alterações dos fatores de coagulação [22].

\section{Efeitos da hipertermia de rebote após a hipotermia terapêutica}

O desenvolvimento de febre nas primeiras 48h após o RCE é comum em pacientes submetidos à HT ou não, porém, a HT parece atenuar esse efeito. A febre está associada à morte em pacientes que não foram submetidos à $\mathrm{HT}$, além disso, o aumento de apenas $1^{\circ} \mathrm{C}$ na temperatura cerebral afeta negativamente a função histológica e funcional [23].

Embora não tenham sido identificados possíveis fatores de risco para a hipertermia de rebote, caracterizada por uma temperatura corporal igual ou maior que $38,5^{\circ} \mathrm{C}$, ela piora a morbidade neurológica e aumenta a mortalidade mesmo em pacientes submetidos à HT [21]. Além disso, a distância entre $36^{\circ} \mathrm{C}$ e a hipertermia é pequena, tornando-se necessário o controle estrito da temperatura, facilitado por um dispositivo computadorizado [25].

Tendo em vista as frequentes descobertas e publicações envolvendo o uso da HT em pacientes com retorno da circulação espontânea pós PCR, o presente estudo fez um apanhado de informações e recomendações recentes envolvendo a atuação do profissional de saúde no âmbito de cuidados intensivos.

Embora a PCR tenha grande repercussão sobre a função neurológica, foi identificada uma falta de padronização em relação à avaliação da evolução clínica, tendo o paciente feito uso de HT ou não. A ressonância magnética ponderada por difusão foi um método considerado confiável, mas ainda necessita de validação através de um estudo prospectivo.

Por sua vez, a bradicardia foi associada a um bom resultado neurológico e há a recomendação de que ela não seja tratada agressivamente durante a indução da $\mathrm{HT}$, desde que a pressão arterial média, a depuração do lactato e a diurese sejam mantidas em valores recomendados. 
Faz-se necessária a frequente atualização dos profissionais de saúde sobre o tema, com o intuito de qualificar a assistência, baseando-se em evidências. Além disso, considera-se importante o desenvolvimento de revisões da literatura científica que promovam a educação continuada.

\section{Referências}

1. Pazin Filho A, Santos JC, Castro RBP, Bueno CDF, Schmidt A. Parada Cardiorrespiratória (PCR). Medicina 2003;36:163-78.

2. Moraes RB, Boniatti MM, Cardoso PRC, Lisboa T, Barros E. Medicina intensiva: consulta rápida. Porto Alegre: Artmed; 2014.

3. American Heart Association. Destaques das Diretrizes da American Heart Association 2015: atualização das diretrizes de RCP e ACE. 2015. Disponível: http://www.perc.ufc.br/wp-content/uploads/2016/02/2015-AHA-Guidelines-HighlightsPortuguese.pdf

4. Gonzalez MM, Timerman S, Gianotto-Oliveira R, Polastri TF, Canesin MF, Lage SG et al. Sociedade Brasileira de Cardiologia. I Diretriz de Ressuscitação Cardiopulmonar e Cuidados Cardiovasculares de Emergência da Sociedade Brasileira de Cardiologia. Arq Bras Cardiol 2013;101(2):Supl 3:1-221.

5. Vancini-Campanharo CR, Vancini RL, Lira CAB, Andrade MS, Góis AFT, Atallah AN. Cohort study on the factors associated with survival post-cardiac arrest. Sao Paulo Med J 2015;133(6):495-501. https://doi.org/10.1590/1516-3180.2015.00472607

6. Alves CA, Barbosa CNS, Faria HTG. Parada Cardiorrespiratória e enfermagem: 0 conceito acerca do suporte básico de vida. Cogitare Enferm 2013;18(2):296-301.

7. Lafetá AFM, Paula BP, Lima CA, Leite LES, Paiva PA, Leão HM et al. Suporte avançado de vida na parada cardiorrespiratória: aspectos teóricos e assistenciais. Revista da Universidade Vale do Rio Verde 2015;13(1):653-63.

8. Thomaz RR, Whitaker IY. Uso da máscara laríngea em pacientes com parada cardiorrespiratória: revisão sistemática. Rev Eletr Enferm 2013;15(3):810-8.

9. Bernoche C, Kopel L, Gianetti NS, Lage SG, Timerman S. Terapia do controle da temperatura pós-parada cardiorrespiratória. Rev Soc Cardiol Estado de São Paulo 2016;26(1):27-33.

10. Souza JE. Hipotermia terapêutica pós reanimação cardiorrespiratória: uma revisão bibliográfica. Revista Recien 2013;3(8):25-35. https://doi.org/10.24276/rrecien2177157X.2013.3.8.25-35

11. Soares CB, Hoga LAK, Peduzzi M, Sangaleti C, Yonekura T, Silva DRAD. Revisão integrativa: conceitos e métodos utilizados em enfermagem. Rev Esc Enferm USP 2014;48(2):335-45. https://doi.org/10.1590/S0080-6234201400002000020

12. Galvão CM. Níveis de evidência. Acta Paul Enferm 2006;19(2):5.

13. Tetsuhara K, Kato H, Kanemura T, Okada I, Kiriu N. Severe acidemia on arrival not predictive of neurologic outcomes in post-cardiac arrest patients. Am J Emerg Med 2016;34(3):425-8. https://doi.org/10.1016/j.ajem.2015.11.030

14. Eid SM, Albaeni A, Vaidya D, Nazarian SM, Llinas R, Chandra-Strobos N. Awakening following cardiac arrest: Determined by the definitions used or the therapies delivered? Resuscitation 2016;100:38-44. https://doi.org/10.1016/j.resuscitation.2015.12.017

15. Ryoo SM, Jeon SB, Sohn CH, Ahn S, Han C, Lee BK et al. Predicting outcome with diffusion-weighted imaging in cardiac arrest patients receiving hypothermia therapy: multicenter retrospective cohort study. Crit Care Med 2015;43(11):2370-7. https://doi.org/10.1097/CCM.0000000000001263

16. Holzinger $\mathrm{U}$, Brunner R, Losert $\mathrm{H}$, Fuhrmann V, Herkner $\mathrm{H}$, Madl $\mathrm{C}$ et al. Resting energy expenditure and substrate oxidation rates correlate to temperature and outcome after cardiac arrest - a prospective observational cohort study. Crit Care 2015;19(1):128. https://doi.org/10.1186/s13054-015-0856-2

17. Williams ML, Nolan JP. Is enteral feeding tolerated during therapeutic hypothermia? Resuscitation 2014;85(11):1469-72. https://doi.org/10.1016/j.resuscitation.2014.08.018

18. Orbo M, Aslaksen PM, Larsby K, Norli L, Schäfer C, Tande PM et al. Determinants of cognitive outcome in survivors of out-of-hospital cardiac arrest. Resuscitation 2014;85(11):1462-8. https://doi.org/10.1016/..resuscitation.2014.08.010

19. Stær-Jensen H, Sunde K, Olasveengen TM, Jacobsen D, Drægni T, Nakstad ER et al. Bradycardia during therapeutic hypothermia is associated with good neurologic 
outcome in comatose survivors of out-of-hospital cardiac arrest. Crit Care Med 2014;42(11):2401-8. https://doi.org/10.1097/CCM.0000000000000515

20. Kamps MJ, Horn J, Oddo M, Fugate JE, Storm C, Cronberg T et al. Prognostication of neurologic outcome in cardiac arrest patients after mild therapeutic hypothermia: a meta-analysis of the current literature. Intensive Care Med 2013;39(10):1671-82. https://doi.org/10.1007/s00134-013-3004-y

21. Winters SA, Wolf KH, Kettinger SA, Seif EK, Jones JS, Bacon-Baguley T. Assessment of risk factors for post-rewarming "rebound hyperthermia" in cardiac arrest patients undergoing therapeutic hypothermia. Resuscitation 2013;84(9):1245-9. https://doi.org/10.1016/. resuscitation.2013.03.027

22. Cho HJ, Kyong YY, Oh YM, Shoi SM, Shoi KH, Oh JS. Therapeutic hypothermia complicated by spontaneous brain stem hemorrhage. Am J Emerg Med 2013;31:266.e1-266e.3. https://doi.org/10.1016/j.ajem.2012.04.017

23. Gebhardt K, Guyette FX, Doshi AA, Callaway CW, Rittenberger JC. The Post Cardiac Arrest Service. Prevalence and effect of fever on outcome following resuscitation from cardiac arrest. Resuscitation 2013;84(2013):1062-7. https://doi.org/10.1016/..resuscitation.2013.03.038

24. Leão RN, Ávila P, Cavaco R, Germano N, Bento L. Hipotermia terapêutica após parada cardíaca: preditores de prognóstico. Rev Bras Ter Intensiva 2015;27(4):322-32. https://doi.org/10.5935/0103-507X.20150056

25. Storm C. O uso de hipotermia e desfechos após ressuscitação cardiopulmonar em 2014. Rev Bras Ter Intensiva 2014;26(2):83-85. https://doi.org/10.5935/0103507X.20140015

26. Hifumi T, Kuroda Y, Kawakita K, Sawano H, Tahara Y, Hase M et al. Effect of admission Glasgow Coma Scale Motor Score on neurological outcome in out-ofhospital cardiac arrest patients receiving therapeutic hypothermia. Circ J. 2015;79(10):2201-8. https://doi.org/10.1253/circj.CJ-15-0308

27. Pang PYK, Wee GHL, Hoo AEE, Sheriff IMT, Lim SL, Tan TE et al. Therapeutic hypothermia in adult patients receiving extracorporeal life support: early results of a randomized controlled study. J Cardiothorac Surg 2016;11:43.

28. Nielsen N, Wetterslev J, Cronberg T, Erlinge D, Gasche Y, Hassager C et al. Targeted temperature management at $33^{\circ} \mathrm{C}$ versus $36^{\circ} \mathrm{C}$ after cardiac arrest. N Engl J Med 2013;369(23):2197-206.

29. Damiani D. Rebaixamento do nível de consciência: abordagem prática na sala de emergência. Arq Bras Neurocir 2016:1-10. https://doi.org/10.1055/s-0036-1594251

30. Hominal M, Picabea S, Meiriño Alejandro, Zapata G. Terapia basada en hipotermia moderada y controlada para el manejo del paro cardiorespiratorio reanimado: Experiencia inicial. Rev Fed Arg Cardiol 2015;45(2):73-8.

31. Corrêa LVO. Hipotermia terapêutica pós-parada cardiorrespiratória em hospitais do extremo sul do Brasil [Dissertação]. Rio Grande: Universidade Federal do Rio Grande; 2014.

32. Waldrigues MC, Wagner BV, Mercês NNA, Perly T, Almeida EA, Caveião C. Complicações da hipotermia terapêutica: diagnósticos e intervenções de enfermagem. J Res Fundam Care 2014;6(4):1666-76. 